\title{
ANÁLISE DOS RESULTADOS OBTIDOS NOS PROCESOS DE AVALIACIÓN DA MATERIA DE FISIOLOXÍA HUMANA DURANTE A COVID-19
}

\author{
Sangiao-Alvarellos, Susana'; de Labra Pinedo, Carmen² \\ ${ }^{1}$ Universidade da Coruña, Departamento de Fisioterapia, \\ Medicina e Ciencias Biomédicas, Facultade de Enfermaría e Podoloxía. \\ https://orcid.org/0000-0003-1207-4667 \\ 2 Universidade da Coruña, Departamento de Fisioterapia, \\ Medicina e Ciencias Biomédicas, Facultade de Enfermaría e Podoloxía. \\ https://orcid.org/0000-0002-5306-0475
}

\section{RESUMO}

Neste traballo presentamos unha análise dos resultados obtidos nos exames finais da materia de Fisioloxía Humana durante a COVID-19, materia impartida no grao de podoloxía da UDC. Estes resultados comparáronse cos obtidos en cursos anteriores en exames levados a cabo de xeito presencial. En todos os casos os resultados proceden de exames tipo test de resposta única. Para levar a cabo esta análise tivéronse en conta os cursos académicos 2017/2018 e 2018/2019, no que analizamos os resultados de 165 exames realizados de xeito presencial e comparámolos cos resultados de 46 exames realizados virtualmente no curso académico 2019/2020. Non se observaron diferencias na cualificación media obtida en ambas modalidades de exames. Non obstante, nos exames virtuais diminúe lixeiramente a porcentaxe de alumnos non presentados e a porcentaxe de suspensos e tres veces máis baixa, sen embargo, tamén diminúe o número de estudantes que obteñen sobresaínte. En base a estes resultados podemos concluír que os exames tipo test virtuais aumentan 0 número de estudantes que supera a materia, pero non así a nota global da mesma.

PALABRAS CLAVE: exames virtuais, fisioloxía, tipo test, avaliación. 


\section{CITA RECOMENDADA:}

Sangiao-Alvarellos, Susana; de Labra Pinedo, Carmen (2021): Análise dos resultados obtidos nos procesos de avaliación da materia de Fisioloxía Humana durante a COVID-19. En García Naya, J.A. (ed.) (2021). Contextos universitarios transformadores: a nova normalidade académica. Leccións aprendidas e retos de futuro. V Xornadas de Innovación Docente. Cufie. Universidade da Coruña. A Coruña (pág. 369-377).

DOl capítulo: https://doi.org/10.17979/spudc. 9788497498180.369

DOl libro: https://doi.org/10.17979/spudc. 9788497498180

\section{ABSTRACT}

In this work we present an analysis of the results obtained in the final exams of the Human Physiology subject during COVID-19, a subject taught in the podiatry degree at the UDC. These results were compared with those obtained in previous academic years in exams carried out face-to-face. In all cases, the results come from single-response multiple-choice tests. To carry out this analysis, the academic years 2017/2018 and 2018/2019 were taken into account, in which we analysed the results of 165 exams taken face-to-face and compared them with the results of 46 exams conducted online in the academic year 2019/2020. No differences were observed in the average qualification obtained in both exam modalities. However, in virtual exams the percentage of students not presented decreases slightly and the percentage of failures is three times lower, however, the number of students who obtain high marks also decreases. Based on these results, we can conclude that online exams increase the number of students who pass the subject, but not the overall mark.

KEY WORDS: Virtual exams, physiology, multiple choice, evaluation. 


\section{INTRODUCIÓN}

A Universidade aparece na Historia a partir da segunda metade do século XII como unha corporación autónoma sobre a que versa 0 saber e a vida intelectual da época ${ }^{1}$. Dende unha perspectiva conceptual, a finalidade última desta institución non variou substancialmente ao longo de nove séculos de historia ao manter, como liña directriz, a súa orientación ao estudo, á aprendizaxe do saber e ao cultivo da ciencia. Con todo, a Universidade debe levar a cabo un esforzo de revisión permanente que lle permita plasmar os seus principios xerais en obxectivos e calidades específicas adecuadas ás distintas continxencias da nosa época. Por iso, fíxose imprescindible unha redefinición da Universidade no seo da sociedade dada a afluencia masiva á mesma de persoas de todas as clases sociais, ó progresivo aumento do grao de especialización en todos os ámbitos do coñecemento, a aparición de novos campos profesionais e 0 cada vez maior intercambio de profesionais formados en distintos países. Neste contexto, creouse o denominado Espazo Europeo de Educación Superior (EEES) cuxos obxectivos se plasman na Declaración de Bolonia (2003) ${ }^{2}$.

0 tratado de Bolonia supuxo un cambio do concepto clásico de Universidade. A adaptación a este novo concepto implica un cambio importante, cunha reforma que obriga a pasar dun modelo de ensino superior regrado a un sistema máis flexible, aberto, e onde se teñen en conta outros factores ademais dos do suposto modelo docente tradicional "clase maxistral e exame", coma o traballo en equipo, procura de información de forma autónoma, capacidade de relación e integración, desenvolvemento persoal... Desta forma preténdese que a Universidade pase dun ensino presencial a unha ensinanza semipresencial; que cambie a súa estrutura dunha universidade cimentada na docencia e 0 ensino, a unha universidade baseada na aprendizaxe e autonomía do alumnado. Seguindo esta premisa debemos planificar 0 ensino-aprendizaxe de forma adecuada para que os alumnos adquiran as competencias, destrezas e habilidades que lles permitan un sólido coñecemento teórico-práctico, un elevado grao de inserción laboral e un alto grao de autoformación ao longo da vida. 
En decembro do 2019 detectouse por primeira vez na cidade de Wuhan, provincia de Hubei, China, un novo coronavirus, denominado coronavirus de tipo 2 causante do síndrome respiratorio agudo severo, SARS-CoV-2. A enfermidade causada por este virus denominouse enfermidade por coronavirus 2019 (COVID-19). Esta enfermidade converteuse rapidamente nunha pandemia e demostrouse que a transmisión persoa a persoa é o principal modo de transmisión. A maiores, o SARS-CoV-2 pode transmitirse durante o período de incubación das persoas co virus. En menos de 6 meses 0 virus xa se transmitira a máis de 200 países, con 10 millóns de casos confirmados e case medio millón de mortes ${ }^{3}$. Neste contexto de emerxencia sanitaria, 014 de marzo do 2020 declárase o Estado de Alarma en España, e a actividade presencial nas Universidades españolas cesa, obrigando ó profesorado a pasar de xeito urxente e inmediato a unha docencia $100 \%$ en liña, para poder seguir desenvolvendo a actividade docente.

A Universidade da Coruña (UDC) conta cun Campus Virtual, baseado en Moodle, unha plataforma educativa adoptada actualmente por moitas universidades españolas para impartir docencia a distancia. Moodle é un sistema de xestión de cursos de libre distribución (Course Management System CMS), que axuda ao profesorado e formadores/as a crear ambientes virtuais de aprendizaxe, utilizando ferramentas de interacción sincrónicas e asincrónicas, de colaboración, de provisión de contidos e actividades, e de avaliación ${ }^{4}$.

Co gallo da aparición do COVID-19, a UDC, ademais de fomentar o uso de Moodle para manter a docencia virtual, tamén estimulou e "habilitou" o uso de Microsoft Teams para este mesmo fin. Microsoft Teams é un espazo de traballo baseado no chat de Office 365, deseñado para mellorar a comunicación e colaboración dos equipos de traballo das empresas, organizacións, universidades... reforzando as funcións colaborativas da plataforma na nube, Office 365 . Teams está integrado de maneira natural con Microsoft Office 365 e baséase en "Groups", 0 servizo na nube desenvolvido para a colaboración entre usuarios. A ferramenta reúne nun espazo común, as aplicacións de colaboración necesarias para traballar en equipo: chats, videoconferencias, notas, acceso a contido, Office Online, planner... Microsoft Teams ofrece a 
posibilidade de utilizar as aplicacións de Office 365 , personalizando a contorna segundo as necesidades de cada equipo, que no caso que nos compete poden ser todos os estudantes matriculados nunha materia, un determinado grupo de prácticas etc.

Tanto as vantaxes como os inconvenientes da docencia en liña foron analizados previamente por numerosos traballos e non van a ser o obxecto deste estudo, neste traballo centrarémonos en avaliar os resultados obtidos nos exames finais, no grao de podoloxía da UDC, nas materias de Fisioloxía dos últimos anos, para desde xeito comparar os exames en liña (situación creada pola COVID-19), cos exames levados a cabo na aula nunha situación habitual. A pregunta a que intentamos dar resposta neste traballo é se son equivalentes os resultados obtidos en exames tipo test realizados de xeito virtual e presencial, e se discriminan de igual xeito os coñecementos adquiridos polo estudantado.

\section{DESCRICIÓN DA EXPERIENCIA}

Ata 0 curso académico 2018-2019, impartíanse no primeiro curso do Grao de Podoloxía da UDC, dúas materias diferentes de fisioloxía, Fisioloxía Xeral e Fisioloxía de Sistemas. Cada unha delas constaba de 6 créditos, e unha impartíase no primeiro cuadrimestre (Fisioloxía Xeral) e outra no segundo (Fisioloxía de Sistemas). A partir do curso académico 2019-2020, e tras unha modificación do plan de estudos de podoloxía, ditas materias fusionáronse nunha soa, con nove créditos e carácter anual (Fisioloxía Humana), e na cal, a parte teórica se imparte integramente dende 0 mes de setembro ata marzo. Debido a que o estado de alarma por mor da COVID-19 se impuxo en España en marzo do 2020, o curso 2019-2020 supuxo unha oportunidade única para estudar a diferenza entre facer exames en liña ou exames presenciais dunha materia impartida $100 \%$ de xeito presencial, a diferenza da maioría das materias avaliadas no segundo cuadrimestre do curso académico 2019-2020, onde os exames foron en liña, pero unha gran parte da materia tamén se impartiu en liña.

Neste traballo centrarémonos exclusivamente nos resultados obtidos nos exames finais dos últimos tres cursos académicos das materias de fisioloxía do primeiro curso do Grao de 
Podoloxía, que en todos os casos foron exames tipo test de resposta única. Non teremos en conta as avaliacións de "recursos" distintos ó exame final. En resumo, para ver os resultados obtidos en exames presenciais tivemos en conta 0 curso académico 2017/2018, no que analizamos os resultados de 76 exames, e o curso 2018/2019, no que analizamos 89 exames. Por outra banda, para ver os resultados de exames realizados de xeito virtual, tivemos en conta 46 exames levados a cabo no curso académico 2019/2020.

En todos os casos, tal como se comentou, os exames realizados foron de modalidade test, con catro posibles respostas e só unha verdadeira. Cada catro preguntas mal contestadas anulábase unha resposta correcta. No caso de exames presenciais, estes leváronse a cabo na propia aula, en papel, onde 0 alumnado marcaba a resposta correcta. Para levar a cabo este exame dispoñían dunha hora onde debían contestar entre 40-50 preguntas. No caso dos exames en liña, os estudantes fixeron os exames de maneira síncrona, dende os seus propios domicilios a través da plataforma Moodle, e cun máximo de tempo de un minuto por pregunta.

\section{RESULTADOS}

Tal como se pode ver na Figura 1, se analizamos a nota media obtida tanto nos exames virtuais coma nos exames presencias, podemos comprobar que non hai diferenzas entre ambas modalidades, obténdose en ambos casos unha media global de 6.5 puntos sobre un máximo de 10 puntos.

Non obstante, cando esmiuzamos os resultados obtidos en ambas modalidades de exames obsérvanse diferenzas claras, tal como se pode apreciar na Figura 2. Diminúe lixeiramente a porcentaxe de alumnos non presentados nos exames virtuais, e a porcentaxe de suspensos foi tres veces máis baixa cando os exames se levaron a cabo de xeito virtual. Claramente podemos ver que hai máis estudantes que obteñen un aprobado na materia, mantense 0 número de notables, pero diminúe o número de estudantes que obteñen sobresaínte cando os exames son virtuais. 


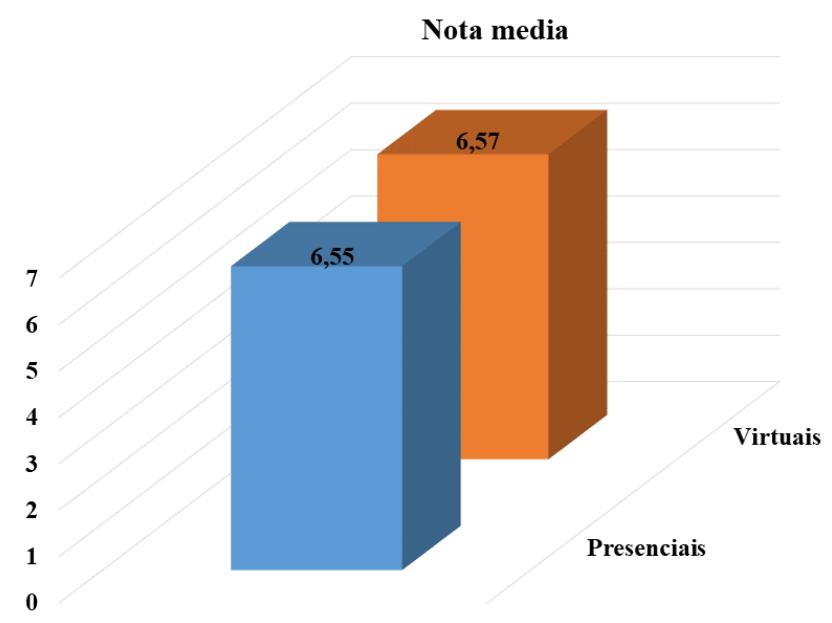

Figura 1. Notas medias obtidas tanto nos exames realizados de xeito virtual (barra laranxa) coma presencial (barra azul). 0 eixo $Y$ representa a cualificación numérica das medias dos exames analizados (165 exames de xeito presencial e 46 de xeito virtual).

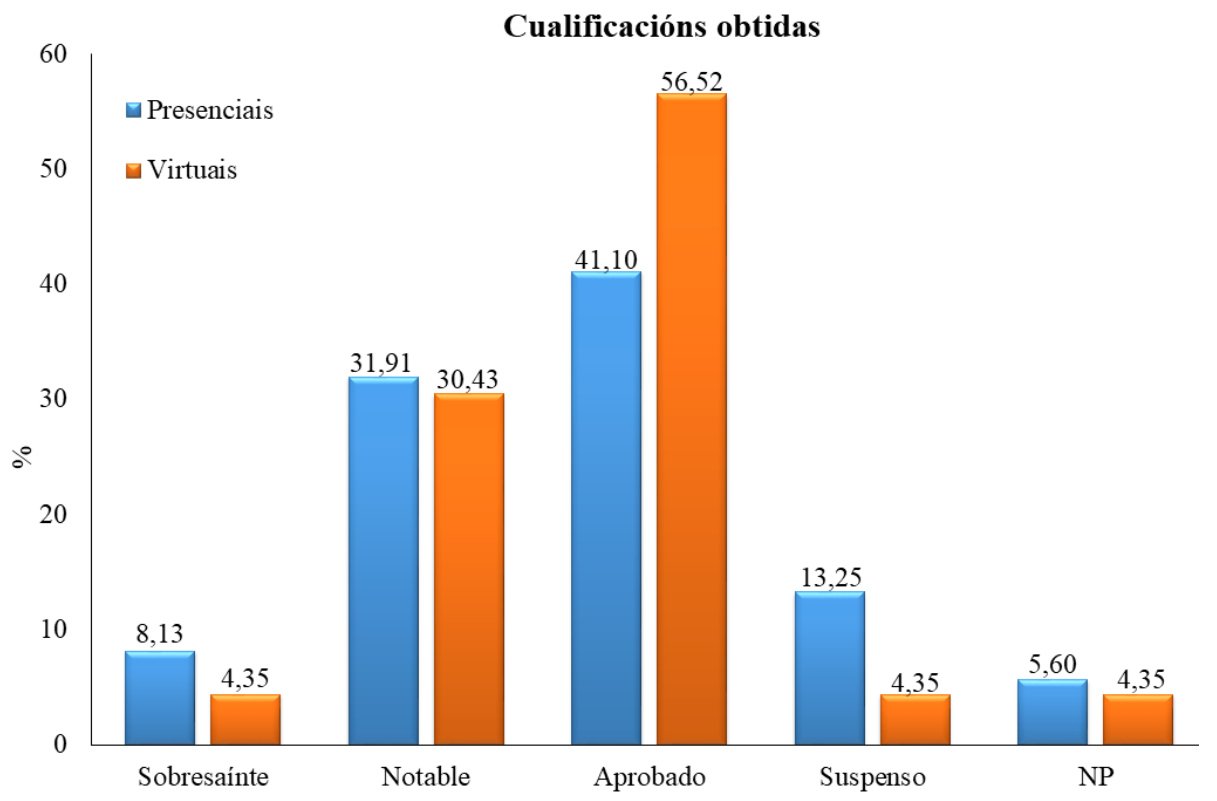

Figura 2. Cualificacións obtidas tanto nos exames realizados de xeito virtual (barra laranxa) coma presencial (barra azul). 0 eixo Y representa a \% de estudantes en cada rango de cualificacións en función dos exames analizados en cada situación (165 exames de xeito presencial e 46 de xeito virtual). $\mathrm{NP}=$ non presentado. 
Todos os resultados aquí obtidos parecen indicar que os exames en liña favorecen que se supere a materia de Fisioloxía Humana, pero non así que se obteñan as cualificacións máximas. Un exame en liña no que as respostas impliquen simplemente a memorización da teoría poden ser máis sinxelos de copiar que os exames presenciais, xa que as respostas poden obterse rapidamente a través do propio material que teñen das clases ou de recursos que poden conseguir en internet (libros electrónicos, bases de datos...) ou incluso poden obter as respostas vía videochamadas/whatsapps cos propios compañeiros ou de persoas alleas. Polo tanto, á hora de deseñar exámenes tipo test para levar a cabo en liña, tivemos en conta dous factores, por unha parte que algunhas das respostas non foran inmediatas, senón que requirisen un certo grao de razoamento, aínda que isto non foi así en todas as respostas pola propia natureza do exame, e por outra parte limitamos o tempo para a realización das probas, para evitar na medida do posible que puidesen "buscar" as respostas. Non obstante, en ningún caso aumentamos a complicación do exame con respecto a cursos anteriores, especialmente porque a materia rematou de impartirse a mesma semana que se decretou 0 estado de alarma en España, e polo tanto, a docencia xa se levara a cabo pensando na realización dun exame final de tipo presencial.

\section{CONCLUSIÓNS}

En base a todos estes resultados podemos concluír que os exames tipo test virtuais, aumentan o número de estudantes que supera a materia de Fisioloxía Humana no grao de podoloxía, pero non así a nota global da mesma. Non obstante, precisamos máis estudos para poder confirmar estes resultados e poder esclarecer os motivos dos mesmos. Preguntas como o tempo óptimo para facer exames virtuais e evitar que os alumnos copien, pero sexan capaces de contestar ás preguntas, aínda seguen sen esclarecerse. Do mesmo modo, precisamos entender e ratificar porque se produce un descenso na porcentaxe de sobresaíntes obtidos. 


\section{REFERENCIAS}

Moncada, J. S. (2008). La Universidad: un acercamiento histórico-filosófico. Ideas y Valores, 57(137), pp. 131-147.

European Ministers of Education. (1999). The European Higher Education Area-Bologna declaration. Bologna on the $19^{\text {th }}$ of June 1999.

Ai L., Jiang L., Xu Z., Yan H., Luo P. \& He Q. (2020). COVID-19 epidemic: a special focus on diagnosis, complications, and management. Expert Rev Clin Pharmacol, 13(10), pp. 1085-1093.

García-Murillo, G., Novoa-Hernández, P. \& Rodríguez, R. S. (2020). Technological Satisfaction About Moodle in Higher Education-A Meta-Analysis. IEEE Revista Iberoamericana de Tecnologias del Aprendizaje, 15(4), pp. 281-290. 
